\title{
Quercetin as an Emerging Anti-Melanoma Agent: A Four-Focus Area Therapeutic Development Strategy
}

\author{
Zoey Harris ${ }^{\dagger}$, Micah G. Donovan', Gisele Morais Branco, Kirsten H. Limesand \\ and Randy Burd*
}

Department of Nutritional Sciences, University of Arizona, Tucson, AZ, USA

Replacing current refractory treatments for melanoma with new prevention and therapeutic approaches is crucial in order to successfully treat this aggressive cancer form. Melanoma develops from neural crest cells, which express tyrosinase - a key enzyme in the pigmentation pathway. The tyrosinase enzyme is highly active in melanoma cells and metabolizes polyphenolic compounds; tyrosinase expression thus makes feasible

OPEN ACCESS

Edited by:

Marcello Iriti,

University of Milan, Italy

Reviewed by:

Muhammad Safder,

University of Karachi, Pakistan

Antonio González Sarrías,

Centro de Edafología y Biología Aplicada del Segura (CSIC), Spain

*Correspondence:

Randy Burd

rburd@email.arizona.edu

tZoey Harris and Micah G. Donovan contributed equally to this work

Specialty section:

This article was submitted

to Food Chemistry,

a section of the journal

Frontiers in Nutrition

Received: 01 August 2016 Accepted: 10 October 2016

Published: 31 October 2016

Citation:

Harris Z, Donovan MG, Branco GM, Limesand $K H$ and Burd $R$ (2016) Quercetin as an Emerging

Anti-Melanoma Agent: A FourFocus Area Therapeutic Development Strategy.

Front. Nutr. 3:48

doi: 10.3389/fnut.2016.00048 a target for polyphenol-based therapies. For example, quercetin $\left(3,3^{\prime}, 4^{\prime}, 5,7\right.$-pentahydroxyflavone) is a highly ubiquitous and well-classified dietary polyphenol found in various fruits, vegetables, and other plant products including onions, broccoli, kale, oranges, blueberries, apples, and tea. Quercetin has demonstrated antiproliferative and proapoptotic activity in various cancer cell types. Quercetin is readily metabolized by tyrosinase into various compounds that promote anticancer activity; additionally, given that tyrosinase expression increases during tumorigenesis, and its activity is associated with pigmentation changes in both early- and late-stage melanocytic lesions, it suggests that quercetin can be used to target melanoma. In this review, we explore the potential of quercetin as an anti-melanoma agent utilizing and extrapolating on evidence from previous in vitro studies in various human malignant cell lines and propose a "four-focus area strategy" to develop quercetin as a targeted anti-melanoma compound for use as either a preventative or therapeutic agent. The four areas of focus include utilizing quercetin to (i) modulate cellular bioreduction potential and associated signaling cascades, (ii) affect transcription of relevant genes, (iii) regulate epigenetic processes, and (iv) develop effective combination therapies and delivery modalities/protocols. In general, quercetin could be used to exploit tyrosinase activity to prevent, and/or treat, melanoma with minimal additional side effects.

Keywords: melanoma, quercetin

Abbreviations: $\alpha$-MSH, alpha-melanocyte-stimulating hormone; AC, adenylyl cyclase; ARE, antioxidant response element; Bax, Bcl-2-associated X protein; cAMP, cyclic adenosine monophosphate; $\mathrm{CpG}$, cytosine-guanine dinucleotide; CREB, cAMP response element-binding protein; Cul3, Cullin-3; DNMT, DNA methyltransferase; ERK, extracellular signal-regulated kinase; GST, glutathione S-transferase; HAT, histone acetyltransferase; HDAC, histone deacetylase; Keap1, Kelch-like ECH-associated protein 1; MAPK, mitogen-activated protein kinase; MC1R, melanocortin 1 receptor; miR, micro-RNA; NQO1, NAD(P)H dehydrogenase [quinone] 1; Nrf2, nuclear factor (erythroid-derived 2)-like 2; PI3K, phosphatidylinositol-4,5-bisphosphate 3-kinase; PKA, protein kinase A; PLA, polylactic acid; PLGA, poly(lactic-co-glycolic acid); POMC, pro-opiomelanocortin; PTEN, phosphatase and tensin homolog; PUMA, p53 upregulated modulator of apoptosis; Q3G, quercetin 3-O-glucoside; Qct, quercetin; Rbx1, RING-box protein 1; ROS, reactive oxygen species; TF, transcription factors; Thio, thioreductase; Ubiq, ubiquitin. 


\section{INTRODUCTION}

Melanoma is an aggressive form of skin cancer that develops from neural crest-derived melanocytes. Due to its metastatic potential, melanoma is the leading cause of death of all skin cancer types, and its incidence and mortality has increased dramatically over the last 30 years. In the United States alone, 76,380 individuals are projected be diagnosed with melanoma in 2016 and 10,130 deaths are estimated to occur (1). The stage of melanoma determines the course of treatment. When diagnosed in its early states, melanoma can often be cured by surgery. However, when diagnosed at the metastatic stages, the prognosis is poor, with the 5-year survival rates of stages III and IV being 45 and $10 \%$, respectively (2-4). As a result of new developments in cancer therapy, treatment at these stages now includes immunotherapy and targeted therapeutic drugs. Yet, despite these new developments, the response rate to such therapies $(\sim 10-20 \%$ for the immunotherapeutic agent, ipilimumab, and $\sim 50 \%$ for the B-RAF inhibitor, dabrafenib) varies depending upon the molecular and genetic profile of the tumor (5-7). With the recent advancements in genomic sequencing, including RNA-seq, single-gene assays, and metabolomics, the unique molecular profile of tumors can now be identified rapidly and cost effectively. By investigating genomic variations, new molecular targets specific to a patient's melanoma can be recognized and utilized for prevention, detection, and treatment.

Functional foods and dietary supplements as anticancer agents have gained interest because of their ability to increase the responsiveness of tumors to current treatments while keeping normal tissue toxicity low. Quercetin, a dietary polyphenol, is one bioactive compound that is of particular therapeutic interest because of its potential to both prevent and treat cancer. At low concentration (e.g., $<100 \mu \mathrm{M}$ ), quercetin induces signaling cascades that lead to the induction of antitumor pathways. At relatively higher concentrations, quercetin can induce damaging cellular effects, including the production of pro-oxidant adducts and the alteration of glutathione (GSH) or bioreduction potential. Studies have also shown a selective sensitivity of melanoma tumor cells to the cytotoxic effects of quercetin (8), whereas normal tissues could be protected through antioxidant activity or the induction of protective cellular signaling pathways (9).

Melanocytes and melanoma cells, in particular, have a unique feature in that they specifically express the oxidative enzyme tyrosinase, which can oxidize quercetin into reactive adducts (10, 11). In this review, we propose that quercetin can be used as a basis for the development of a strategy for melanoma therapeutics. By exploiting the characteristics of quercetin and the expression of tyrosinase, therapies could be developed that specifically target melanoma and preserve or protect normal tissue. With modern genomic sequencing and drug delivery mechanisms, quercetinbased therapeutics could provide a great therapeutic advantage and positively impact prevention and treatment of melanoma. To use quercetin as an antitumor agent, several limitations must be overcome. This review proposes four focus areas to develop quercetin as anticancer compound. The four focus areas include utilizing quercetin to (i) modulate cellular bioreduction potential and associated signaling cascades, (ii) affect transcription of relevant genes, (iii) regulate epigenetic processes, and (iv) develop effective combination therapies and delivery modalities/ protocols. By focusing on these areas, quercetin could be used to exploit tyrosinase activity, as well as prevent, and/or treat, melanoma with minimal additional side effects.

\section{OVERVIEW OF MELANOMA}

Melanoma is characterized as a malignant tumor that often originates from pigment-producing melanocytes. Melanocytes are derived from neural crest cells, which are embryonic cells that have the ability to migrate to specific locations, where they can then differentiate into specific cells, including mature melanocytes (12). There are a large array of melanocyte populations, and their location spans multiple regions including the skin, meninges, mucosal surfaces, ear, and eye (13). The formation of melanoma then arises from a series of steps. The first step, known as the horizontal and radial growth phase, occurs when certain mutations in melanocytes lead to an increase in proliferative capacity (14). Progression to the vertical growth stage occurs when the altered melanocytes enter the dermis and/or hypodermis of the skin. Once the tumor cells invade the endothelium, they can travel to other locations within the body, thus leading to metastatic melanoma (15). Determinants of melanoma are influenced by both environmental (i.e., sunlight UV) and genetic factors. Such factors can influence the expression of the pigment-producing enzyme, tyrosinase, which has been shown to increase in tumors arising from melanocytes (16).

Several pathways are proposed to influence melanoma development, such as the RAS/RAF/MAPK, PI3K/AKT, and Notch pathways. Specifically, single base substitution mutations in two key genes involved in the MAPK signaling pathway, B-RAF and N-RAS, are commonly associated with development of melanoma (17-19). The most common oncogenic mutation in melanoma occurs in the serine/threonine kinase B-RAF gene at the 600 position, where a valine is replaced by either an arginine (V600K) or glutamic acid (V600E). Many studies have observed constitutive activation of ERK signaling in nude mice harboring the $\mathrm{B}-\mathrm{RAF}^{\mathrm{V} 600 \mathrm{E}}$ mutation, leading to higher rates of proliferation and transformation (20-24). Although this mutation commonly occurs in melanoma, it should be noted that the mutation itself is not sufficient to cause cancer since it is also found in benign melanocytic lesions $(17,19,25)$.

Likewise, the phosphoinositol-3-kinase-AKT (PI3K-AKT) pathway is also involved in melanomagenesis, and its activation often leads to increased cell survival, proliferation, and motility. Activation of this pathway in melanoma has been attributed to oncogenic mutations in the N-RAS gene as well as loss of expression or function of the tumor suppressor protein, PTEN (26). N-RAS mutations have been shown to activate the PI3K-AKT pathway via the direct binding to PI3K or through accumulation of activated RAS-GTP $(27,28)$. Although independent from N-RAS mutations, loss of PTEN is often found concurrently with the BRAF mutation mentioned above. Concurrent loss of PTEN with the BRAF mutation often leads to activation and cross talk between the MAPK and PI3K-AKT pathways (29). One study showed increased melanoma invasiveness in mice expressing 
melanocyte-specific $\mathrm{BRAF}^{\mathrm{V} 600 \mathrm{E}}$ with consecutive PTEN gene silencing, in comparison to mice expressing $\mathrm{BRAF}^{\mathrm{V} 600 \mathrm{E}}$ alone (30).

Involvement of the Notch pathway in melanoma development also plays an important role. Upregulation of the Notch receptors has been observed in malignant melanoma lesions, and activation of this pathway often leads to increased cell survival and growth (31). An in vivo study investigating the expression of Notch receptors in multiple uveal melanoma cell lines observed an increase in tumor growth, while suppression of the pathway utilizing short hairpin RNA segments that targeted the Notch2 receptor displayed a reduction in tumor growth (32).

In recent years, advances in the knowledge of the pathways described above and their role in metastatic melanoma have led to the development of new therapeutic agents. Until recently, the prognosis for advanced malignant melanoma was poor, and the only treatments approved by the Food and Drug Administration (FDA) were dacarbazine and IL-2. Even with these available treatment options, the 5-year survival rate and median overall survival were $6 \%$ and 7.5 months, respectively $(4,33)$. Recent advances in molecular profiling of tumors and immunotherapy have led to the development of new FDA-approved agents for metastatic melanoma, including the immune-checkpoint inhibitor, ipilimumab (34), and the BRAF inhibitor, vemurafenib (35). Ipilimumab's mechanism of action allows for a prolonged antitumor T-cell response to malignant melanocyte antigens (34). One randomized, double-blind study evaluated the response of multiple doses of ipilimumab and found that a $10 \mathrm{mg} / \mathrm{kg}$ dose elicited a median overall survival rate of $\sim 11$ months (7). Other treatment options for metastatic melanoma include dabrafenib (36), another BRAF inhibitor used specifically in patients with the $\mathrm{BRAF}^{\mathrm{V} 600 \mathrm{E}}$ mutation, as well as trametinib (25), a MEK1/2 inhibitor used specifically in patients with the $\mathrm{BRAF}^{\mathrm{V} 600 \mathrm{E} / \mathrm{K}}$ mutation. Table 1 shows current FDA-approved drugs for melanoma therapy including immune therapies, targeted therapies, and chemotherapeutics. For more information on the current treatments, we refer readers to the review by Maverakis et al. (37). Multiple phases II and III melanoma trials studying the effect of combination treatments are currently underway. However, due to the evolving resistance to such drugs and the adverse effects they

TABLE 1 | Current FDA-approved therapies for melanoma.

\begin{tabular}{lll}
\hline Type of therapy & Drug name & Mechanism of action \\
\hline Immunotherapy & Interferon alfa-2b & IFNAR/JAK/STAT activation \\
& Interleukin-2 & Immune cell activation \\
& Ipilimumab & Anti-CTLA-4 monoclonal antibody \\
& Nivolumab & Anti-PD-1 monoclonal antibody \\
& Pembrolizumab & Anti-PD-1 monoclonal antibody \\
& Talimogene & Oncolytic viral therapy \\
Targeted & laherparepvec & \\
therapies & Cobimetinib & MEK inhibitor \\
& Dabrafenib & BRAFV00E inhibitor \\
& Trametinib & MEK-1/2 inhibitor \\
Chemotherapy & Vemurafenib & BRAFV00E inhibitor \\
& Dacarbazine & DNA alkylating \\
& Temozolomide & DNA alkylating/methylating \\
\hline
\end{tabular}

List of types of the therapy and specific drugs with corresponding mechanisms of action, currently in use for melanoma treatment. carry, more effective combination treatments are still needed. Specifically, there is a need to prevent the induction of melanoma or develop combination therapies that target the unique molecular profile of melanoma tumors.

\section{QUERCETIN}

The development of agents that produce limited side effects in prevention or therapy protocols is highly important. Dietary compounds as anticancer agents have gained attention because of the recent elucidation of their mechanisms of action. Flavonoids, for example, are a group of bioactive polyphenolic compounds that hold promise in the prevention and treatment of melanoma. More than 4,000 varieties of flavonoids are present in nature (38) and were first identified and isolated by Szent-Gyorgyin in 1936 (39). They are classified into seven main categories based upon variations in their heterocyclic C-ring, namely, flavones (e.g., apigenin, luteolin, and diosmetin), flavonols (e.g., quercetin, myricetin, and kaempferol), flavanones, isoflavones, catechins, anthocyanins, and chalcones $(38,40)$. Even though flavonoids are considered non-nutrients, they are important components of the human diet, presenting numerous beneficial health effects.

Quercetin derivatives account for $60 \%$ of the total flavonoids ingested daily and are the most abundant and important dietary flavonoids present in the human diet (41). The derivatives are commonly found in many vegetables and fruits, such as red onions, apples, berries (e.g., cranberries, strawberries, dark cherries, and blue berries), parsley, olive oil, cocoa, citrus fruits, tea, and red wine $(42,43)$. The estimated daily intake of quercetin varies according to food habits and can range between 5 and $40 \mathrm{mg}$ a day, although these levels may rise up to $200-500 \mathrm{mg} /$ day depending on the consumption of certain beverages, such as red wine and tea, in combination with a diet high in vegetables and fruits $(44,45)$. The potential toxicity of quercetin is quite low as human studies failed to demonstrate any adverse effects when quercetin was administered orally in single doses of $4 \mathrm{~g}$ or $500 \mathrm{mg}$ thrice daily (46-48). Similarly, studies have reported no toxicity in humans with intake up to $1 \mathrm{~g}$ /day (42). This observation represents a critical factor that favors the utilization of quercetin in combination with standard cancer therapeutics.

Flavonoids are the most widely found compounds of plant phenolics. Their basic chemical structure is composed of diphenylpropanes (C6-C3-C6) with two aromatic rings linked through a pyran ring. Quercetin is classified as one of the best-described flavonoids. This compound possesses hydroxyl groups $(-\mathrm{OH})$ attached to the $3,5,7,3^{\prime}$, and $4^{\prime}$ positions (Figure 1). It may be present in plants and fruits in several different glycosidic forms in which one or more sugar groups are linked to phenolic groups by glycosidic linkage (49). For instance, quercetin forms the glycosides, quercitrin and rutin, together with rhamnose and rutinose sugars, respectively. Unlike quercetin glycosides, aglycone quercetin is not a normal dietary component.

The distribution, absorption, and metabolism of polyphenoliccontaining foods, including quercetin, have been greatly studied in human and animal models in order to elucidate the biological activity and the ability of these compounds to enter cells. Quercetin is commonly found as a glycoside, which contains a 


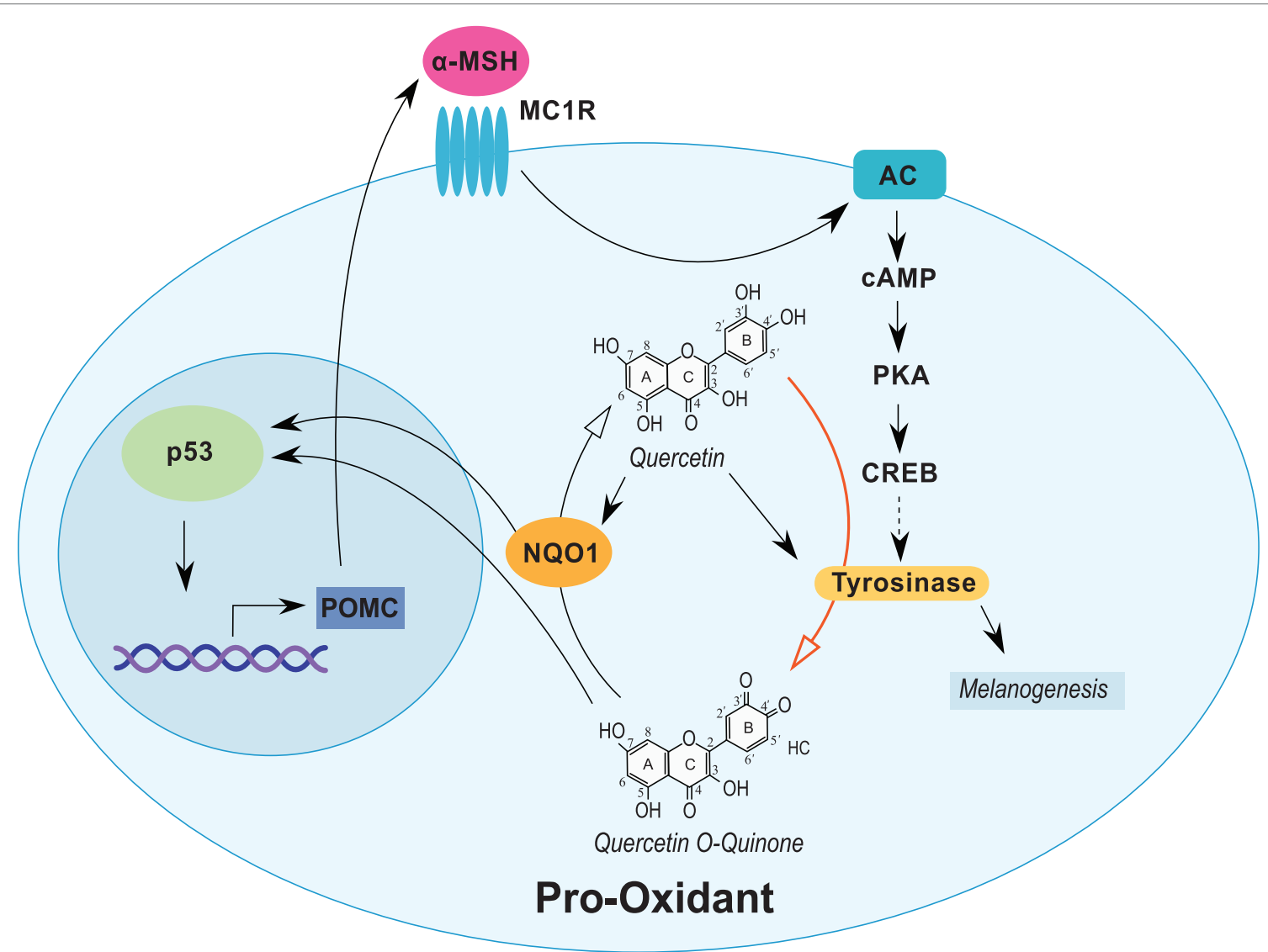

FIGURE 1 Quercetin induces tyrosinase and stress response proteins in melanocytic cells. Expression of tyrosinase in melanocytic cells is induced through the $\alpha-\mathrm{MSH}$ pathway. Quercetin induces the expression of tyrosinase and several stress-responsive proteins, including NQO1 and p53. Tyrosinase oxidizes quercetin (red arrow) into an o-quinone and other reactive compounds that induce NQ01 and p53. NQO1 stabilizes p53 and can recycle activated quercetin back into the parent compound. Expression of p53 can also stimulate $\alpha$-MSH activity completing a cyclical response to quercetin exposure. Open arrows indicate biochemical reactions. Closed arrows represent induction/stimulus.

sugar group bound to phenolic groups by glycosidic linkage (49). Present in a broad variety of vegetables, isoquercetin [quercetin 3-O-glucoside $(\mathrm{Q} 3 \mathrm{G})]$, represents a quercetin glycoside with a sugar at the 3-position (49). Aglycones (the forms lacking sugar moieties) occur less frequently.

Although not completely understood, numerous studies have shown that quercetin and other flavonoids are subject to hydrolysis and metabolic conversion during their absorption in the intestinal epithelial cell before reaching the bloodstream $(49,50)$. It is generally accepted that dietary quercetin glycosides are mainly hydrolyzed to the aglycone forms by intracellular $\beta$-glucosidases, which are subsequently converted into $3^{\prime}$-O-methylquercetin (isorhamnetin) and, to a smaller extent, into $4^{\prime}$-methoxyquercetin (tamaraxetin) $(50,51)$. It may also be sulfated or glucuronidated at one of the hydroxyl groups in the absorptive cells of the intestinal epithelium and the liver (52-54). Following this process, the resulting quercetin derivatives and any remaining unmetabolized quercetin are released into the circulation via the hepatic system.

Despite the difficulty in determining how quercetin is metabolized, several studies have confirmed that it reaches systemic circulation. Dietary studies in humans and animals have been performed and extensively reviewed (55); however, the number of studies is limited, and the quercetin administration protocol varies widely between studies, including differences in chemical composition of the compound administered, delivery medium, purity, and length of exposure. Pharmacokinetic studies in humans (56) and animals (57) demonstrate active metabolism and significant chemical modification. Additionally, consideration of the mixed polyphenols in the diet and their impact on absorption are important (58) as is the potential for synergy (59). Many polyphenols have anticancer properties with different mechanisms of action, bioavailability, and potency (60), and it is important to consider how multiple polyphenols interact.

In humans, Egert et al. administered 50, 100, or $150 \mathrm{mg} /$ day quercetin orally for 2 weeks, and plasma levels were elevated by 178,359 , and $570 \%$, respectively (54). Other studies conducted on animal and human models also confirmed the presence of quercetin metabolites and conjugates in blood samples $(47,61)$. Several studies demonstrate the formation of conjugates following metabolism. The most commonly observed metabolites in circulation involve conjugation with glucuronides and/or sulfates, and methylated forms of these metabolites. Glutathione 
conjugates have also been observed but are likely restricted to enzymatic activity in the liver (62). It is, however, important to consider what role cellular effects of these conjugates play, and how it may differ from pure quercetin is an important question.

Pertaining to melanoma prevention or therapy, the exact form and concentration of quercetin in skin are unknown. There is evidence that quercetin does have biological activity in skin. For example, quercetin mitigated radiation-induced skin fibrosis following oral administration in $\mathrm{C} 3 \mathrm{H} / \mathrm{HeN}$ mice (63). For detailed descriptions of the pharmacokinetics including bioavailability, metabolism, and biodistribution of quercetin and related polyphenolic compounds, we refer readers to the review articles by Cai et al. (64), and Kawabata et al. (65). We also refer readers to a review by Biasutto et al., which discusses potential insights and mechanisms to improve the bioavailability and bioefficacy of polyphenolic compounds (66). The limited number of clinical studies using quercetin that investigate oral bioavailability, the effect of supplementation protocols, and mechanisms of action, limits the ability to rationally design clinical protocols. Although quercetin holds promise, more clinical studies are required to fully realize the benefit of quercetin.

However, the rapid metabolism and low bioavailability is of concern especially with therapeutic applications. It is therefore proposed that long-term and low-dose dietary quercetin would be ideal for preventative protocols, but to achieve therapeutic applications, the compound must be used as an adjuvant and more technologically advanced delivery mechanisms must be utilized.

\section{BIOREDUCTION POTENTIAL AND ASSOCIATED SIGNALING CASCADES}

Biological and pharmacological studies suggest that dietary polyphenols, such as quercetin, exhibit antioxidant, anti-inflammatory, antiproliferative, anti-obesogenic, anticancer, and other properties $(11,67,68)$. In particular, the role of quercetin in anticancer activity has been established and extensively reviewed in vitro (69). Etiology and progression of many diseases are directly related to the oxidative stress generated by an imbalance between the formation and neutralization of pro-oxidants (70-74). Beneficial effects of quercetin on normal tissues have been attributed to several mechanisms, especially antioxidant effects. Within the flavonoid family, quercetin is the most potent scavenger of reactive oxidative species (ROS), and its anti-oxidative capacity is mainly due to the presence of phenolic hydroxyl groups on the B-ring and at the 3-position (49). At low concentrations, quercetin acts as an antioxidant by donating electrons to unstable ROS that have the potential to damage cellular DNA. Such damage can lead to mutations and influence the transformation of cancer cells that would be critically important in cancer prevention studies (11).

Quercetin's anticarcinogenic effects have also been directly associated with its pro-oxidative properties in colon cancer, hepatoma, and melanoma cells $(8,75-77)$. Some studies have shown that the effects of quercetin are dependent on the concentration in tissue, mode of metabolism, and bioavailability (78). High concentrations of quercetin (e.g., 40-100 $\mu \mathrm{M}$ ) likely promote pro-oxidant effects through oxidation of quercetin into o-quinone and the formation of reactive species, which culminate in apoptosis. Alternatively, low concentrations $(<40 \mu \mathrm{M})$ have been shown to exert antioxidant properties $(9,79)$. Therefore, the biphasic nature of quercetin has the potential to be used as a dietary component for prevention of cancer at low doses and an adjuvant therapy to conventional cancer treatments at higher doses.

The biosynthesis of melanin and other pigments in melanocytes are catalyzed by tyrosinase, a copper-containing enzyme (80). In melanoma, the effect of quercetin can be amplified due to tyrosinase activity (Figure 1). Importantly, tyrosinase expression in melanocytic tumors increases during tumorigenesis (81). Enzymatic action catalyzed by tyrosinase utilizes quercetin as a substrate, which can form reactive o-quinone compounds (82). The activation of quercetin into quinone compounds has been observed in various cell lines, including melanoma cells $(10,11)$. Subsequently, after the formation of reactive species and metabolized quercetin, the compounds can bind to and deplete GSH, the main bioreductive antioxidant agent to prevent cellular damage (83). Additionally, the generation of ROS may directly trigger p53 induction and p53-mediated gene transcription and/or cell death through p53-independent apoptosis. The increase in ROS can also trigger endoplasmic reticulum stress (9) and the induction of mitochondrial proteins such as NOXA, p53, and PUMA with subsequent activation of procaspases 3 and 9 (84).

\section{TRANSCRIPTION OF RELEVANT GENES}

The role quercetin plays in the induction of p53 is critical to anticancer therapies because of the potent transcriptional activity of p53 (Figure 2). In DB-1 melanoma cells overexpressing tyrosinase, quercetin administration led to significant increase of p53 protein and the number of cells in apoptosis compared to untreated cells (8). In particular, quercetin may potentiate p53-dependent apoptosis in melanocytic cells via stimulation of nuclear factor E2-related factor 2 (Nrf2) transcriptional activity, which has been observed in various cell types including human hepatoblastoma HepG2 cells $(85,86)$, human BJ foreskin fibroblasts and skin HaCaT keratinocytes (87), rat DI TNC1 astrocytes (88), and UVA-irradiated mouse B16F10 melanoma cells (89). Nrf2 is a basic leucine zipper (bZIP) transcription factor that induces the expression of several genes involved in cellular redox reactions, drug metabolism and transport, energy metabolism, and intracellular iron homeostasis in response to oxidative and electrophilic stress (90). A particular Nrf2 target gene of interest is NQO1, which encodes the cytoplasmic protein $\mathrm{NAD}(\mathrm{P}) \mathrm{H}$ dehydrogenase [quinone] 1 (NQO1) (90). NQO1 is a FAD-binding reductase that catalyzes two-electron reductions of quinone compounds, using NADH and NADPH as electrondonating cofactors (91). It has been demonstrated that NQO1 stabilizes p53 and prevents its ubiquitin-independent degradation (92-96) via a physical protein-protein interaction $(92,97)$. Given that the majority of melanomas (80-90\%) express wild-type p53 proteins (98), upregulation of NQO1 by quercetin-mediated Nrf2 activity may provide potential means for targeted anti-melanoma therapy. Indeed, in DB-1 cells, upregulation of p53 was observed in parallel with increased NQO1 protein (8). 

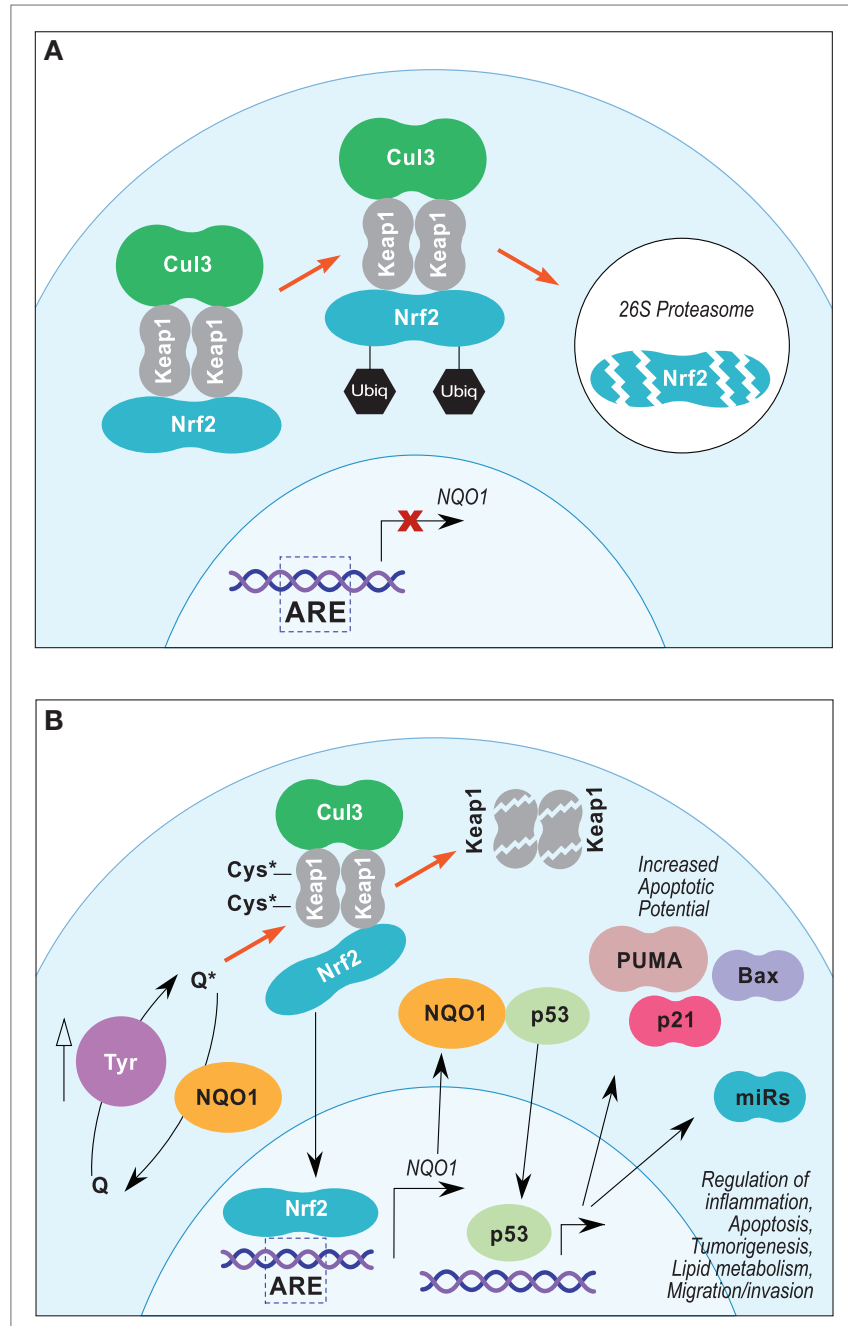

FIGURE 2 | (A,B) Proposed Nrf2/ARE pathway leading to NQO1-mediated p53 stabilization in melanoma. (A) In steady-state conditions, Nrf2 transcriptional activity is suppressed by Keap1, which sequesters Nrf2 in the cytosol and facilitates Cul3-dependent ubiquitinylation and 265 proteasomal degradation. (B) Electrophilic stress at key cysteine residues of Keap1 leads to disassociation of Keap1/NRF2-DLG interface, which inhibits Cul3dependent ubiquitinylation and promotes Keap1 degradation. Degradation of Keap1 protein allows accumulation of Nrf2 and translocation into the nucleus, which promotes expression of NQO1 and other genes under the control of AREs. Stabilization of p53 by NQ01 may potentiate expression of proapoptotic proteins and miRNAs.

Nrf2 target gene activation is dependent on its nuclear translocalization and heterodimerization with small Maf proteins $(90,99)$. Nrf2-Maf heterodimers activate gene transcription by binding antioxidant response element (ARE) consensus sequences (5- ${ }^{\mathrm{A} /} \mathrm{G}-\mathrm{TGA}^{-}{ }^{\mathrm{C}} \mathrm{G}-\mathrm{NNNGC}{ }^{\mathrm{A} /} \mathrm{G}-3$ ) located in the regulatory regions of their target genes $(99,100)$. Nrf2 transcriptional activity is regulated in part by posttranslational ubiquitindependent proteasomal degradation and is induced in the presence of several electrophilic compounds, such as hydroquinones and quinones (91). Under normal conditions (Figure 2A), Nrf2 levels are constitutively repressed via Kelch-like ECH-associated protein 1 (Keap1)-dependent ubiquitylation by a Cullin-3 (Cul3) and RING-box protein 1 (Rbx1) E3 ubiquitin ligase complex (90). Under oxidative and electrophilic stress (Figure 2B), Nrf2 is stabilized, and its accumulation leads to increased ARE activation (90). Keap1 is an electrophile sensor protein that contains critical cysteine residues in the BTB (Cys151) and intervening region (IVR) (Cys273 and Cys288) domains (101). Modification of the nucleophilic cysteine residues of Keap1 by electrophilic Nrf2 inducers inhibits Cul3-Rbx1 ubiquitin ligase activity and stabilizes Nrf2 (90).

Single-particle electron microscopy data suggest a "hinge and latch model" for Nrf2 regulation by the Keap1/Cul3-Rbx1 complex (102). This model proposes that C-terminal Kelch-repeat domains of Keap1 homodimers bind a single Nrf2 protein at the DLG and ETGE motifs within the Neh2 domain (103). Binding at the Keap1-ETGE interface has $\sim 2$ orders of magnitude higher binding affinity than at the Keap1-DLG interface, which can be disrupted under oxidative and electrophilic stimulus $(90,103)$. An intact Keap1-DLG interface ("closed hinge") puts Nrf2 in the optimal position for ubiquitylation by Cul3-Rbx1. Conversely, destabilization of the Keap1-DLG interface ("open hinge") prevents the ubiquitylation and degradation of Nrf2 and increases ARE transcriptional activation (90). Although the exact mechanism remains to be fully elucidated, interruption of Keap1-DLG binding is likely the result of conformational changes brought on by modification of key cysteine residues of Keap 1 by electrophilic Nrf2 inducers (90).

Quercetin has been demonstrated to induce Nrf2-mediated ARE activation in vitro in human hepatoblastoma HepG2 cells $(85,86)$, human BJ foreskin fibroblasts and skin HaCaT keratinocytes (87), rat DI TNC1 astrocytes (88), and UVAirradiated mouse B16F10 melanoma cells (89). Tanigawa et al. demonstrated the ability of quercetin treatment to upregulate ARE transcription by regulating both Nrf2 and Keap1 in HepG2 cells (85). Quercetin treatment at a range of concentrations $(5-40 \mu \mathrm{M})$ led to an increase in NQO1 protein levels, which was paralleled by increases in Nrf2 mRNA. This effect was attenuated by pretreatment with actinomycin $\mathrm{D}$, which suggested that quercetin mediates Nrf2 expression, in part, at the transcriptional level. Quercetin also stabilized Nrf2 protein and decreased steady-state turnover by inhibiting Cul3-Rbx1dependent ubiquitylation, which increased Nrf2 $t_{1 / 2}$ reduction time by fourfold and suggests quercetin may prevent $26 \mathrm{~S}$ proteasomal degradation of Nrf2. Finally, quercetin decreased levels of Keap1 protein but had no effect on Keap1 mRNA expression or ubiquitylation, suggesting it may downregulate Keap1 protein levels through a $26 \mathrm{~S}$ proteasome-independent degradation mechanism. The upregulation of Nrf2 expression and stabilization of Nrf2 protein, coupled with decreased Keap1, leads to accumulation of Nrf2 in the nucleus and induction of Nrf2/ARE-activated target genes (85). Other studies in HepG2 cells suggest that the effect of quercetin on Nrf2 activation may be dose dependent (86). At lower concentrations $(5-10 \mu \mathrm{M})$, quercetin significantly increased the nuclear translocation of Nrf2 and the nuclear content of phosphorylated Nrf2, whereas higher concentrations $(50 \mu \mathrm{M})$ decreased both phospho-Nrf2 levels and the nuclear/cytosolic Nrf2 ratio (86). 
Schadich et al. was able to demonstrate that quercetin administration in human BJ foreskin fibroblasts and aneuploid immortalized skin HaCaT keratinocytes led to significant upregulation of Nrf2 activity, as determined by a luciferase reporter assay (87). Nrf2 activity was increased in both cell lines treated with either $40 \mu \mathrm{g} / \mathrm{mL}$ of ginger extract or $30 \mu \mathrm{M}$ of quercetin for $10 \mathrm{~h}$. Western blot analysis showed increased levels of glutathione$S$-transferase P1 (GSTP1) protein, a downstream target of Nrf2 activity, in BJ fibroblasts but not in $\mathrm{HaCaT}$ keratinocytes. It was suggested that the refractory response to upregulation of GSTP1 protein in $\mathrm{HaCaT}$ by activated Nrf2 is likely due to constitutively high expression in these types of cells, indicating a potentially distinct role of GSTP1 in HaCaT keratinocytes compared to normal cells (87). In immortalized rat DI TNC1 astrocytes, a range of quercetin concentrations $(2.5-10 \mu \mathrm{M})$ attenuated lipopolysaccharide (LPS)-induced NF- $\kappa \mathrm{B}$ activity and upregulated Nrf2 activity in both the presence and absence of LPS (88). Treatment with $10 \mu \mathrm{M}$ of quercetin led to $\sim 20$-fold and 25 -fold increase in Nrf2 activity in LPS-free and LPS-containing media, respectively, as determined by luciferase assay (88).
Loss of Nrf2 activity appears to play a role in melanogenesis (89). In primary human epidermal melanocytes and mouse B16F10 melanoma cells, siRNA-mediated silencing of Nrf2 enhances melanogenesis after UVA-radiation exposure (89). In B16F10 cells, UVA radiation alone significantly decreased Nrf2 nuclear translocation and ARE-luciferase activity $1 \mathrm{~h}$ post-irradiation. Pretreatment with quercetin (15 and $30 \mu \mathrm{M})$ $30 \mathrm{~m}$ before UVA exposure increased Nrf2 translocation and ARE-luciferase activity compared to control cells not treated with quercetin (89).

\section{REGULATION EPIGENETIC CHANGES}

Epigenetic alterations have recently been suggested to play a role in the initiation of carcinogenesis and induction of pro-cancer characteristics; thus, epigenetic modifying compounds have been proposed as anticancer agents (104-106). Quercetin has the potential to elicit significant epigenetic changes across multiple cell and tissue types (Table 2) (107-115). Specific epigenetic changes attributed to quercetin include changes in DNA methylation,

TABLE 2 | Epigenetic activity elicited by quercetin.

\begin{tabular}{|c|c|c|c|c|c|c|}
\hline $\begin{array}{l}\text { Epigenetic } \\
\text { activity }\end{array}$ & Specific outcome & $\begin{array}{l}\text { Experimental } \\
\text { model }\end{array}$ & $\begin{array}{l}\text { Concentration/ } \\
\text { dose }\end{array}$ & $\begin{array}{l}\text { Exposure } \\
\text { time }\end{array}$ & Analytical method & Reference \\
\hline \multirow{5}{*}{$\begin{array}{l}\text { DNA } \\
\text { methylation }\end{array}$} & DNMT inhibition & In vitro reaction & $\mathrm{IC} 50=1.6 \mu \mathrm{M}$ & $30 \mathrm{~m}$ & ${ }^{3} \mathrm{H}$-radioactivity assay & Lee et al. (107) \\
\hline & DNMT inhibition & $\begin{array}{l}\text { Human PC3 and } \\
\text { DU145 prostate } \\
\text { cancer cell lines }\end{array}$ & $12 \mu \mathrm{M}$ & $\begin{array}{l}24,48 \\
\text { and } 72 \mathrm{~h}\end{array}$ & Colorimetric assay & $\begin{array}{l}\text { Sharma et al. } \\
(108)\end{array}$ \\
\hline & CpG demethylation & $\begin{array}{l}\text { Human PC3 and } \\
\text { DU145 prostate } \\
\text { cancer cells }\end{array}$ & $12 \mu \mathrm{M}$ & $48 \mathrm{~h}$ & Bisulfite sequencing & $\begin{array}{l}\text { Sharma et al. } \\
(108)\end{array}$ \\
\hline & CpG demethylation & $\begin{array}{l}\text { Human RKO } \\
\text { colon cancer cells }\end{array}$ & $1 \mu \mathrm{M}$ & $120 \mathrm{~h}$ & MSP & Tan et al. (109) \\
\hline & CpG demethylation & $\begin{array}{l}\text { Human } 9706 \\
\text { esophageal } \\
\text { cancer cells }\end{array}$ & $\begin{array}{l}40 \mu \mathrm{M} \\
\text { (nanoliposomal } \\
\text { delivery) }\end{array}$ & $48 \mathrm{~h}$ & MSP & $\begin{array}{l}\text { Zheng et al. } \\
(110)\end{array}$ \\
\hline \multirow[t]{4}{*}{$\begin{array}{l}\text { Histone } \\
\text { modification }\end{array}$} & H3 acetylation & $\begin{array}{l}\text { Human HL-60 } \\
\text { leukemia cells }\end{array}$ & 75 and $100 \mu \mathrm{M}$ & $\begin{array}{l}3,6, \text { and } \\
12 \mathrm{~h}\end{array}$ & $\begin{array}{l}\text { Western blot and } \\
\text { ChIP assay }\end{array}$ & Lee et al. (111) \\
\hline & HAT activation/HDAC inhibition & $\begin{array}{l}\text { Human HL-60 } \\
\text { leukemia cells }\end{array}$ & $100 \mu \mathrm{M}$ & $6 \mathrm{~h}$ & Colorimetric assay & Lee et al. (111) \\
\hline & HDAC inhibition & $\begin{array}{l}\text { Human } 9706 \\
\text { esophageal } \\
\text { cancer cells }\end{array}$ & $\begin{array}{l}40 \mu \mathrm{M} \\
\text { (nanoliposomal } \\
\text { delivery) }\end{array}$ & $48 \mathrm{~h}$ & $\begin{array}{l}\text { Immunocytochemical } \\
\text { assay }\end{array}$ & $\begin{array}{l}\text { Zheng et al. } \\
(110)\end{array}$ \\
\hline & HDAC inhibition & $\begin{array}{l}\text { Human HepG2 } \\
\text { liver cancer cells }\end{array}$ & $\begin{array}{l}40 \text { and } 80 \mu \mathrm{M} \\
\text { (nanoparticle } \\
\text { delivery) }\end{array}$ & $24 \mathrm{~h}$ & $\begin{array}{l}\text { Colorimetric assay } \\
\text { and Western blot }\end{array}$ & $\begin{array}{l}\text { Bishayee et al. } \\
(112)\end{array}$ \\
\hline \multirow[t]{3}{*}{$\begin{array}{l}\text { Micro-RNA } \\
\text { expression }\end{array}$} & miR-155 downregulation & $\begin{array}{l}\text { Murine RAW264.7 } \\
\text { macrophages }\end{array}$ & $\begin{array}{l}10 \mu \mathrm{M} \text { quercetin } \\
\text { and } 10 \mu \mathrm{M} \\
\text { isorhamnetin }\end{array}$ & $6 \mathrm{~h}$ & Two-step RT-PCR & $\begin{array}{l}\text { Boesch- } \\
\text { Saadatmandi } \\
\text { et al. (113) }\end{array}$ \\
\hline & Hepatic miR-125b and miR-122 upregulation & C57B6/j mice & $\begin{array}{l}2 \mathrm{mg} / \mathrm{g} \text { enriched } \\
\text { diet }\end{array}$ & 6 weeks & Two-step RT-PCR & $\begin{array}{l}\text { Boesch- } \\
\text { Saadatmandi } \\
(114)\end{array}$ \\
\hline & $\begin{array}{l}\text { Hepatic upregulation of miR-467b, miR-374*, miR-30c-1, } \\
\text { miR-450a-5p, miR-30b*, miR-197, miR-137, miR-466c-5p, } \\
\text { miR-335-5p, miR-10b, miR-29a*, miR-196a, miR-7b, miR- } \\
\text { 190, miR-335-3p, miR196b, let-7c-2* and downregulation } \\
\text { of miR-671-5p, miR-878-3p, miR-466f-3p, miR-486, miR- } \\
\text { 451, miR-144, miR-291b-5p, miR-324-5p, miR-296-5p, } \\
\text { miR290-3p, let-7f*, miR-429, miR-298, let-7b* }\end{array}$ & Apo $E^{-/-}$mice & $\begin{array}{l}30 \mathrm{mg} / \text { day } \\
\text { supplemental }\end{array}$ & 2 weeks & Microarray analysis & $\begin{array}{l}\text { Milenkovic } \\
\text { et al. (115) }\end{array}$ \\
\hline
\end{tabular}

Compilation of studies documenting quercetin's effect on epigenetic activity. 
histone acetylation, and micro-RNA (miR) expression. Although there is currently a lack of information regarding the epigenetic effects of quercetin specifically in melanocytes or melanoma, the epigenetic effects observed in other tissues likely play a role in the pathogenesis of malignant melanoma. Therefore, this area of research is critical to advancing prevention or therapeutic approaches.

Inhibition and reversal of aberrant methylation on tumor suppressor genes may represent a significant target mechanism in cancer prevention and therapy (106). DNA methylation reactions are catalyzed by DNA methyltransferases (DNMTs), of which multiple forms are expressed in humans and other mammals (107). DNMT1 is the most abundant form expressed in humans and functions as a maintenance methyltransferase with high affinity for hemimethylated DNA. DNMT3A and DNMT3B are also expressed in humans and function as de novo methyltransferases with similar affinity to both hemimethylated and unmethylated CpG sites (116). Prokaryotic SssI DNMT is a bacterially derived de novo DNMT with functional similarities to DNMT3A and DNMT3B (107).

Quercetin inhibits both human DNMT1- and SssI DNMTmediated DNA methylation in a dose-dependent manner $\left(\mathrm{IC}_{50}=1.6 \mu \mathrm{M}\right)$, as determined by an in vitro DNMT activity assay; however, this effect was dependent on the presence of catechol-O-methyltransferase (COMT) (107). Double-stranded dinucleotides ( $\sim 2 \mathrm{~mol}$ CpG sites) were incubated with DNMTs, the methyl donor $S$-adenosyl-L-methionine (SAM, containing $\sim 0.5 \mu \mathrm{Ci}$ of [methyl ${ }^{3} \mathrm{H}$ ]SAM), and a range of quercetin concentrations, and DNMT activity was determined by scintillation counting (107).

Quercetin has also demonstrated DNMT inhibitory effects in human PC3 and DU145 prostate cancer cells, RKO colon cancer cells, and Eca9706 esophageal cancer cells (108-110). The combination of quercetin $(12 \mu \mathrm{M})$ and curcumin $(14 \mu \mathrm{M})$ significantly decreased methylation at specific CpG sites within the AR promoter of both PC3 and DU145 prostate cancer cell lines, as determined by sodium bisulfite sequencing (108).

p 16 INK $4 \alpha$ is an important tumor suppressor protein involved in cellular senescence by preventing CDK-dependent phosphorylation of $\mathrm{Rb}$ (117). Silencing of $\mathrm{p} 16 \mathrm{INK} 4 \alpha$ is associated with development of multiple tumor types, and the loss of the $\mathrm{p} 16 \mathrm{INK} 4 \alpha / \mathrm{Rb}$ is suggested to contribute to melanomagenesis (118). Venza and colleagues investigated the epigenetic control of p16INK $4 \alpha$ in clinical cutaneous $(n=60)$ and uveal $(n=6)$ melanoma tissue sections compared to normal skin samples $(n=48)(119)$. It was found that $63.33 \%(n=38)$ and $50 \%(n=3)$ of cutaneous and uveal melanomas, respectively, did not express p $16 \mathrm{INK} 4 \alpha \mathrm{mRNA}$, and $15 \%(n=9)$ of cutaneous melanomas displayed expression levels below the cutoff point established in healthy samples. Of the 38 cutaneous samples with absent expression, 76.31\% $(n=29)$ had aberrant homozygous hypermethylation within the p16INK4 $\alpha$ promoter, and all 9 samples with low p16INK4 $\alpha$ expression had heterozygous methylation (119). Another study using 59 clinical metastatic cutaneous melanoma samples found that p16INK4 $\alpha$ was methylated in $25 \%$ of samples $(n=15)$ and that promoter methylation was significantly overrepresented in samples harboring NRAS mutations (120).
Administration of quercetin $(1 \mu \mathrm{M})$ alone inhibited growth of human RKO colon cancer cells and restored p16INK4 $\alpha$ gene expression in a dose-dependent manner, which was associated with a significant reversal of hypermethylation of the p 16 INK $4 \alpha$ promoter (109). Similar effects have been observed in human Eca9706 esophageal cancer cells using nanoliposomal delivery of quercetin $(40 \mu \mathrm{M})$, which suppressed cell growth, increased apoptosis, and increased p16INK4 $\alpha$ expression (110). Increased p16INK $4 \alpha$ expression was associated with decreased p $16 \mathrm{INK} 4 \alpha$ gene methylation, as determined by MSP, and decreased expression of DNMT1 (110).

Methylation of several other tumor suppressor genes has been observed to increase in melanoma including RAR-b2, GATA4, WIF1, SOCS1, RASSF1A, TFP12, MINT17, and MINT 31 (121). It is likely that the methylation status of these factors and other tumor suppressor genes, including $\mathrm{p} 16 \mathrm{INK} 4 \alpha$, are sensitive to treatment with demethylating agents such as quercetin, which may play a role in prevention and therapy of melanoma.

Histone acetylation, which refers to the addition of an acetyl group on specific amino acid residues on histone proteins, represents another epigenetic regulatory factor that may be targeted by quercetin in cancer prevention and therapy (122). Quercetin may also affect histone acetylation and subsequent gene expression by regulating histone acetyl transferase (HAT) and histone deacetylase (HDAC) activity (110-112). Activation of HATs by quercetin $(100 \mu \mathrm{M})$ has been demonstrated in human HL-60 leukemia cells, which was associated with increased acetylation of histone 3 and FasL-related apoptosis (111). Treatment with quercetin also inhibited HDAC activity (111), which has also been observed in Eca9706 cells $(40 \mu \mathrm{M})(110)$ and human HepG2 liver cancer cells (40 and $80 \mu \mathrm{M})(112)$.

Overall, evidence of the effect of quercetin on key cancer-driving epigenetic modifications in melanoma is lacking. However, given that epigenetic activity, such as aberrant methylation of tumor suppressor genes, is associated with melanomagenesis, this is a field that is largely open for further exploration to enhance preventative and therapeutic strategies.

\section{COMBINATION THERAPIES AND DELIVERY}

Melanoma is an aggressive form of cancer that is refractory to current therapies. Additionally, as discussed above, bioavailability of quercetin is low, and as a food component, its anticancer potency is limited compared to pharmaceuticals. On the other hand, there are minimal side effects associated with dietary or systemic administration of quercetin, even at high levels. Thus, quercetin could be used in combination with other cytotoxic drugs, provided that bioavailability is addressed through chemical modification or use of a delivery system. Quercetin affects multiple signaling cascades and gene transcription, which also makes it a desirable adjuvant to biologicals. For example, there is new evidence suggesting the emergence of drug resistance to some of the newly approved FDA biological therapeutics in the treatment of advanced melanoma. Of particular interest are dabrafenib and trametinib. Dabrafenib is a selective inhibitor of the kinase, $\mathrm{B}-\mathrm{RAF}^{\mathrm{V} 600}$, which causes upregulation of the MAPK pathway and is commonly mutated in over $50 \%$ of patients with 
metastatic melanoma $(20,123)$. This leads to further inhibition of B-RAF ${ }^{\mathrm{V} 600}$ 's downstream targets, MEK1/2 and ERK, and thus decreased levels of cell survival and proliferation. Trametinib, on the other hand, functions to inhibit MEK1 and MEK2, also leading to reduced cell survival and proliferation. Resistance to these drugs has been attributed to activation of non-MAPK pathways (PI3K/Akt/mTOR), adaptive upregulation of Akt, overexpression of RTKs, and mutations in MEK (124-126). These mechanisms can significantly reduce the ability of both trametinib and dabrafenib to exert their antiproliferative effects and usually results in a reduced survival rate. Mechanistically, quercetin inhibits multiple pathways and could be an ideal candidate as an adjunct with current therapies, such as dabrefenib and trametinib (Figure 3). Quercetin (10-40 $\mu \mathrm{M})$ displays dose-dependent attenuation of PI3K/Akt and MAPK signaling in UVB-irradiated B16F10 melanoma cells (127). This effect was observed in parallel with reduced cell viability, increased apoptosis, and enhanced nuclear translocation of NF- $\kappa \mathrm{B}$, a downstream effector in the PI3K/Akt pathway (127). A recent study in cervical cancer lines also demonstrated a dose-dependent decrease in levels of both phosphorylated PI3K and Akt, as well as of translocation of NF-kB (128). Similar effects were seen in another study where co-administration of quercetin and temozolomide decreased the levels of phosphorylated Akt more than temozolomide alone in glioblastoma cells (129). Quercetin was also shown to suppress the activity of PI3K through directly binding in an H-Ras-transformed MCF10A human breast epithelial cell line (130). These studies suggest that quercetin could be used in combination with current BRAF and MEK inhibitors to aid in the inhibition of pathways used for proliferation and survival in melanoma.

In addition to enhancing drugs that target signaling pathways, quercetin has shown efficacy in improving cytotoxic therapies such as temozolamide, which is commonly used to treat melanoma. For example, a recent study demonstrated that quercetin increased the effect of glioblastoma treatment compared to standard chemoradiotherapy alone through the inhibition of PI-3-kinase-Akt pathway. The study utilized cell lines, and the greatest reduction in cell viability and colony formation was observed when cells were treated with a combination therapy that included quercetin (129). Several studies have also addressed quercetin bioavailability in combination treatments. For example, a study analyzed liposomes loaded with quercetin and temozolomide to enhance the chemosensitization of drug-resistant cancer cells. The study demonstrated that DSPE-PEG2000 polymeric liposomes were an effective nanocarrier for enhancing drug delivery to tumors (131).

More novel approaches to compensate for the low bioavailability of quercetin have been made using liposomes, PLGA, PLA, chitosan, silica, and other compounds (69). Specifically designed nanosystems have proven to be effective at increasing bioavailability, such as the use of quercetin nanocrystals and nanoparticles. A recent in vitro study found that the efficiency of quercetin-loaded PLA nanoparticles was $\sim 97 \%$, and the nanoparticle encapsulation significantly improved the bioavailability of quercetin (132). Another study investigating the effects of nanocrystals found that its solubility was significantly higher compared to quercetin alone (133). Other important advances include the use of nanoparticles to improve solubilization of quercetin for increased oral uptake. For example, a quercetin-containing self-nanoemulsifying drug delivery system (Q-SNEDDS) was developed to increase quercetin oral bioavailability (134). Optimization of the delivery system significantly improved quercetin transport into cells grown as a monolayer. Oral ingestion resulted in rapid gut uptake following administration and resulted in peak plasma concentration, approximately twofold to threefold over control, $24 \mathrm{~h}$ after administration. Overall, the results suggested that Q-SNEDDS was a potent formulation that increased solubility and bioavailability through oral administration. Overall, the use of nanoparticles as a delivery platform for quercetin provides encouraging possibilities for therapeutic administration at high doses. Additional platforms can be used to co-deliver quercetin, such as co-administration of chemotherapies and drugs or biological therapeutics $(135,136)$, and can also be targeted to specific melanoma or tumor markers (Figure 3). These new emerging strategies of increasing quercetin bioavailability may further enhance quercetin's effects in combination with current drugs that target tumor cells; however, more research and clinical testing is needed (69), especially in treatment protocol development to maximize tumor toxicity of the combinations and avoid any attenuation effects by the antioxidant properties of quercetin (137).

\section{CONCLUSION}

Quercetin has great potential to be used an antitumor agent in melanoma, and various preventative and therapeutic options can be developed. This review has outlined four specific areas, that with further investigation, could facilitate the development of quercetin into an anticancer compound (Figure 3). The polyphenolic food compound has several desirable characteristics that can be exploited by targeting cells that express tyrosinase. The oxidation of quercetin can lead to a potentiation of its pro-oxidant effects such as an increase in p53 and Nrf2. There are several transcriptional events that result from quercetin treatment, which long term may aid in the prevention of melanoma or can be used to compliment current therapies. Activation of tyrosinase (oxidation) leads to enhancement of quercetin's pro-oxidant effects and can also induce several signaling pathways, at least indirectly. Little is known about quercetin and its affect on epigenetic processes in melanoma, but observing other cancers as reference warrants investigation into this emerging area of prevention and therapy. Although data on quercetin's influence on epigenetic changes in the skin and in melanoma are currently lacking, sufficient data exist to demonstrate quercetin's capacity to elicit epigenetic changes in other tissues types.

Another future area that should be addressed is the induction of miRNA. Changes in miRNA expression have been suggested to play a role in human diseases such as cancer and cardiovascular disease among others (138). MiRNAs function to negatively regulate gene expression by repressing the translation of target mRNA sequences (139). Quercetin has demonstrated the capacity to 


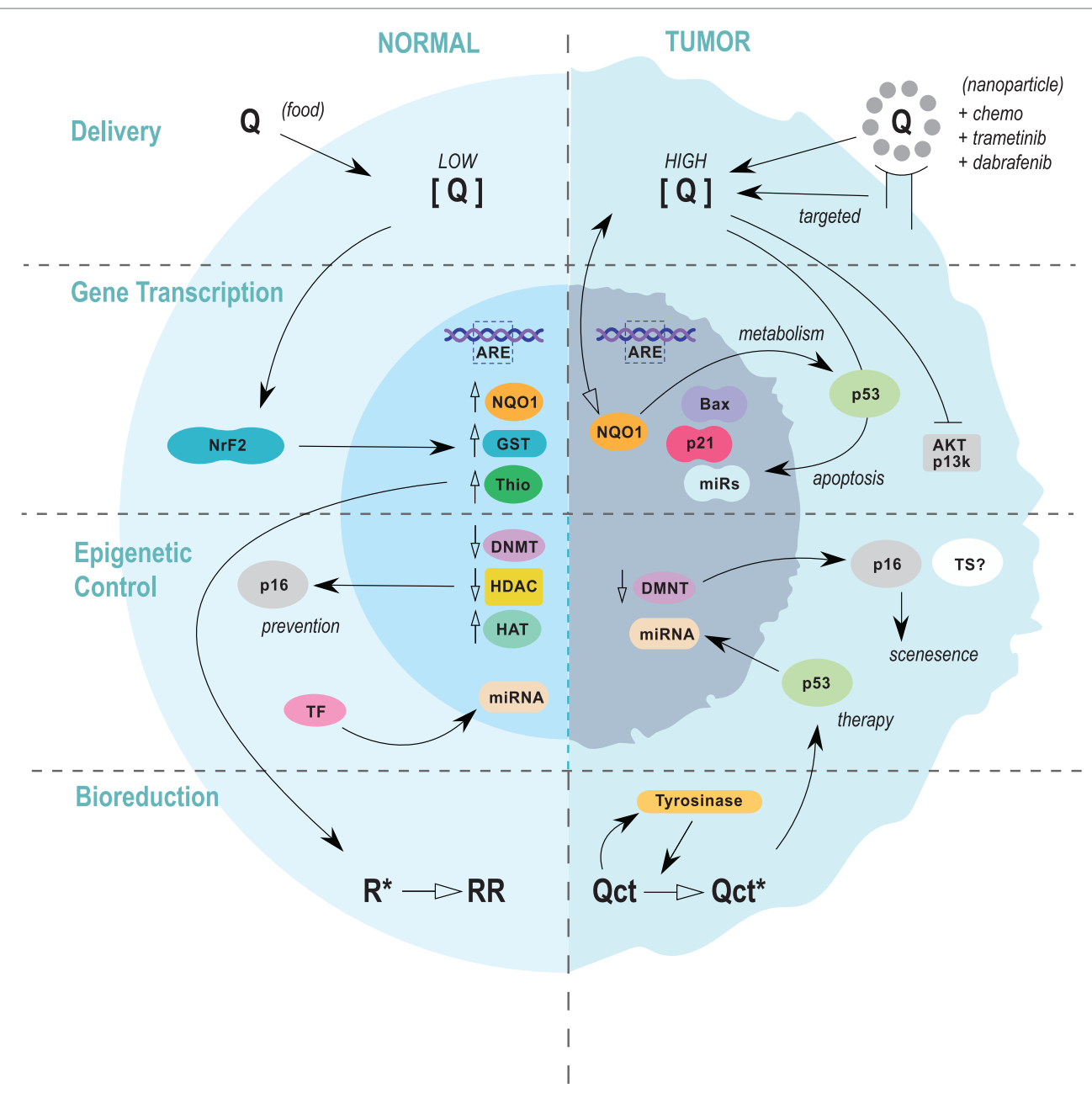

FIGURE 3 | Summary of the four focus areas to develop quercetin as a chemo-preventative or therapeutic agent. In melanoma prevention scenarios (left), quercetin would be ingested through food sources and the concentration in normal melanocytes would be relatively low. Antioxidant activities and signaling pathways leading to the induction of cytoprotective proteins would dominate. Evidence suggests that quercetin may impart transcriptionally permissive epigenetic modifications within key tumor suppressor genes, including p16, which could confer resistance to oncogenesis. Induction of miRNAs could also aid in cancer prevention. In therapeutic protocols (right), quercetin would be delivered alone or in combination with anti-melanoma pharmaceuticals. Quercetin and additional compounds could be delivered through nanoparticles targeted to melanoma cells, or in an untargeted regimen. Pro-oxidant effects would be desired, and induction of wild-type p53 and other apoptotic factors would aid in therapy. Epigenetic mechanisms would likely be more prominent in prevention (blue line), but miRNAs have been shown to play a significant role in circumventing drug resistance.

affect miRNA expression in both cell culture and animal models. The effect of a quercetin-rich diet on miRNA expression has also been investigated in human lung cancer cases from the EAGLE case-control study (140).

Four focus areas were proposed to develop quercetin as a targeted anti-melanoma compound for use as either a preventative or therapeutic agent (Figure 3). Overall quercetin could be used to exploit tyrosinase activity to prevent, and/or treat, melanoma with minimal additional side effects. Dietary intake would be suitable in the development of preventative approaches, while nanoparticle systems will be required to achieve effective concentrations of quercetin for therapeutic approaches, likely as an adjuvant to melanoma-specific biologicals or possibly chemotherapeutics.

\section{AUTHOR CONTRIBUTIONS}

$\mathrm{ZH}$ is the author of the manuscript and participated in concept development. MD is the author of the manuscript, contributed equally with $\mathrm{ZH}$, and participated in concept development. GB and $\mathrm{KL}$ participated in writing and concept development. RB participated in the writing, organization, and development of the overall manuscript concept.

\section{FUNDING}

This material is based upon work that is supported by the National Institute of Food and Agriculture, U.S. Department of Agriculture, under award number 2014-70003-22358. 


\section{REFERENCES}

1. American Cancer Society. Cancer Facts \& Figures 2016. (2016). p. 1-9.

2. Gray-Schopfer V, Wellbrock C, Marais R. Melanoma biology and new targeted therapy. Nature (2007) 445:851-7. doi:10.1038/nature05661

3. Cummins DL, Cummins JM, Pantle H, Silverman MA, Leonard AL, Chanmugam A. Cutaneous malignant melanoma. Mayo Clin Proc (2006) 81:500-7. doi:10.4065/81.4.500

4. Balch CM, Gershenwald JE, Soong S-J, Thompson JF, Atkins MB, Byrd DR, et al. Final version of 2009 AJCC melanoma staging and classification. J Clin Oncol (2009) 27:6199-206. doi:10.1200/jco.2009.23.4799

5. Weber J, Thompson JA, Hamid O, Minor D, Amin A, Ron I, et al. A randomized, double-blind, placebo-controlled, phase II study comparing the tolerability and efficacy of ipilimumab administered with or without prophylactic budesonide in patients with unresectable stage III or IV melanoma. Clin Cancer Res (2009) 15:5591-8. doi:10.1158/1078-0432.ccr-09-1024

6. O'day SJ, Maio M, Chiarion-Sileni V, Gajewski TF, Pehamberger $H$, Bondarenko IN, et al. Efficacy and safety of ipilimumab monotherapy in patients with pretreated advanced melanoma: a multicenter single-arm phase II study. Ann Oncol (2010) 21:1712-7. doi:10.1093/annonc/mdq013

7. Wolchok JD, Neyns B, Linette G, Negrier S, Lutzky J, Thomas L, et al. Ipilimumab monotherapy in patients with pretreated advanced melanoma: a randomised, double-blind, multicentre, phase 2, dose-ranging study. Lancet Oncol (2010) 11:155-64. doi:10.1016/s1470-2045(09)70334-1

8. Thangasamy T, Sittadjody S, Lanza-Jacoby S, Wachsberger PR, Limesand $\mathrm{KH}$, Burd R. Quercetin selectively inhibits bioreduction and enhances apoptosis in melanoma cells that overexpress tyrosinase. Nutr Cancer (2007) 59:258-68. doi:10.1080/01635580701499545

9. Vargas AJ, Burd R. Hormesis and synergy: pathways and mechanisms of quercetin in cancer prevention and management. Nutr Rev (2010) 68:418-28. doi:10.1111/j.1753-4887.2010.00301.x

10. Kubo I, Nitoda T, Nihei K-I. Effects of quercetin on mushroom tyrosinase and B16-F10 melanoma cells. Molecules (2007) 12:1045-56. doi:10.3390/ 12051045

11. Metodiewa D, Jaiswal AK, Cenas N, Dickancaité E, Segura-Aguilar J. Quercetin may act as a cytotoxic prooxidant after its metabolic activation to semiquinone and quinoidal product. Free Radic Biol Med (1999) 26:107-16. doi:10.1016/s0891-5849(98)00167-1

12. Cichorek M, Wachulska M, Stasiewicz A, Tymińska A. Skin melanocytes: biology and development. Postepy Dermatol Alergol (2013) 30:30-41. doi:10.5114/pdia.2013.33376

13. Sullivan RJ, Fisher DE. Understanding the biology of melanoma and therapeutic implications. Hematol Oncol Clin North Am (2014) 28:437-53. doi:10.1016/j.hoc.2014.02.007

14. Herlyn M, Thurin J, Balaban G, Bennicelli JL, Herlyn D, Elder DE, et al. Characteristics of cultured human melanocytes isolated from different stages of tumor progression. Cancer Res (1985) 45:5670-6. doi:10.1007/978-1-4613-1751-7_1

15. Liu J, Fukunaga-Kalabis M, Li L, Herlyn M. Developmental pathways activated in melanocytes and melanoma. Arch Biochem Biophys (2014) 563:13-21. doi:10.1016/j.abb.2014.07.023

16. Quaglino P, Osella-Abate S, Cappello N, Ortoncelli M, Nardò T, Fierro MT, et al. Prognostic relevance of baseline and sequential peripheral blood tyrosinase expression in 200 consecutive advanced metastatic melanoma patients. Melanoma Res (2007) 17:75-82. doi:10.1097/cmr. 0b013e328054c667

17. Chin L, Garraway LA, Fisher DE. Malignant melanoma: genetics and therapeutics in the genomic era. Genes Dev (2006) 20:2149-82. doi:10.1101/ gad.1437206

18. Miller AJ, Mihm MC. Melanoma. N Engl JMed (2006) 355:51-65. doi:10.1056/nejmra052166

19. Tsao H, Chin L, Garraway LA, Fisher DE. Melanoma: from mutations to medicine. Genes Dev (2012) 26:1131-55. doi:10.1101/gad.191999.112

20. Davies H, Bignell GR, Cox C, Stephens P, Edkins S, Clegg S, et al. Mutations of the BRAF gene in human cancer. Nature (2002) 417:949-54. doi:10.1038/ nature00766

21. Garnett MJ, Marais R. Guilty as charged: B-RAF Is a human oncogene. Cancer Cell (2004) 6:313-9. doi:10.1016/j.ccr.2004.09.022
22. Houben R, Becker JC, Kappel A, Terheyden P, Bröcker EB, Goetz R, et al. Constitutive activation of the Ras-Raf signaling pathway in metastatic melanoma is associated with poor prognosis. J Carcinog (2004) 3:6. doi:10.1186/1477-3163-3-6

23. Wan PT, Garnett MJ, Roe SM, Lee S, Niculescu-Duvaz D, Good VM, et al. Mechanism of activation of the RAF-ERK signaling pathway by oncogenic mutations of B-RAF. Cell (2004) 116:855-67. doi:10.1016/S0092-8674(04) 00215-6

24. Wellbrock C, Ogilvie L, Hedley D, Karasarides M, Martin J, Niculescu-Duvaz $\mathrm{D}$, et al. V599EB-RAF is an oncogene in melanocytes. Cancer Res (2004) 64:2338-42. doi:10.1158/0008-5472.can-03-3433

25. Flaherty KT, Robert C, Hersey P, Nathan P, Garbe C, Milhem M, et al. Improved survival with MEK inhibition in BRAF-mutated melanoma. NEngl J Med (2012) 367:107-14. doi:10.1056/nejmoa1203421

26. Kwong LN, Davies MA. Navigating the therapeutic complexity of PI3K pathway inhibition in melanoma. Clin Cancer Res (2013) 19:5310-9. doi:10.1158/1078-0432.ccr-13-0142

27. Barbacid M. Ras genes. Annu Rev Biochem (1987) 56:779-827. doi:10.1146/ annurev.biochem.56.1.779

28. Rodriguez-Viciana P, Warne PH, Khwaja A, Marte BM, Pappin D, Das P, et al. Role of phosphoinositide 3-OH kinase in cell transformation and control of the actin cytoskeleton by Ras. Cell (1997) 89:457-67. doi:10.1016/ s0092-8674(00)80226-3

29. Davies MA, Fox PS, Papadopoulos NE, Bedikian AY, Hwu W-J, Lazar AJ, et al. Phase I study of the combination of sorafenib and temsirolimus in patients with metastatic melanoma. Clin Cancer Res (2012) 18:1120-8. doi:10.1158/1078-0432.ccr-11-2436

30. Dankort D, Curley DP, Cartlidge RA, Nelson B, Karnezis AN, Damsky WE Jr, et al. BrafV600E cooperates with Pten loss to induce metastatic melanoma. Nat Genet (2009) 41:544-52. doi:10.1038/ng.356

31. Nickoloff BJ, Osborne BA, Miele L. Notch signaling as a therapeutic target in cancer: a new approach to the development of cell fate modifying agents. Oncogene (2003) 22:6598-608. doi:10.1038/sj.onc.1206758

32. Asnaghi L, Ebrahimi KB, Schreck KC, Bar EE, Coonfield ML, Bell WR, et al. Notch signaling promotes growth and invasion in uveal melanoma. Clin Cancer Res (2012) 18:654-65. doi:10.1158/1078-0432.ccr-11-1406

33. Barth A, Wanek LA, Morton DL. Prognostic factors in 1,521 melanoma patients with distant metastases. J Am Coll Surg (1995) 181:193-201.

34. Hodi FS, O’Day SJ, McDermott DF, Weber RW, Sosman JA, Haanen JB, et al. Improved survival with ipilimumab in patients with metastatic melanoma. $N$ Engl J Med (2010) 363:1290-1290. doi:10.1056/nejmx100063

35. Chapman PB, Hauschild A, Robert C, Haanen JB, Ascierto P, Larkin J, et al. Improved survival with vemurafenib in melanoma with BRAF V600E mutation. N Engl J Med (2011) 364:2507-16. doi:10.1056/NEJMoa1103782

36. Hauschild A, Grob J-J, Demidov LV, Jouary T, Gutzmer R, Millward M, et al. Dabrafenib in BRAF-mutated metastatic melanoma: a multicentre, open-label, phase 3 randomised controlled trial. Lancet (2012) 380:358-65. doi:10.1016/s0140-6736(12)60868-x

37. Maverakis E, Cornelius L, Bowen G, Phan T, Patel F, Fitzmaurice S, et al. Metastatic melanoma - a review of current and future treatment options. Acta Derm Venereol (2015) 95:516-24. doi:10.2340/00015555-2035

38. Boly R, Gras T, Lamkami T, Guissou P, Serteyn D, Kiss R, et al. Quercetin inhibits a large panel of kinases implicated in cancer cell biology. Int J Oncol (2011) 38:833-42. doi:10.3892/ijo.2010.890

39. Harborne JB. Nature, distribution and function of plant flavonoids. Prog Clin Biol Res (1986) 213:15-24.

40. Aherne SA, O'brien NM. Protection by the flavonoids myricetin, quercetin, and rutin against hydrogen peroxide-induced DNA damage in caco-2 and Hep G2 cells. Nutr Cancer (1999) 34:160-6. doi:10.1207/ s15327914nc3402_6

41. O’Prey J, Brown J, Fleming J, Harrison PR. Effects of dietary flavonoids on major signal transduction pathways in human epithelial cells. Biochem Pharmacol (2003) 66:2075-88. doi:10.1016/j.bcp.2003.07.007

42. Harwood M, Danielewska-Nikiel B, Borzelleca J, Flamm G, Williams G, Lines T. A critical review of the data related to the safety of quercetin and lack of evidence of in vivo toxicity, including lack of genotoxic/carcinogenic properties. Food Chem Toxicol (2007) 45:2179-205. doi:10.1016/j.fct. 2007.05.015 
43. Spagnuolo C, Russo M, Bilotto S, Tedesco I, Laratta B, Russo GL. Dietary polyphenols in cancer prevention: the example of the flavonoid quercetin in leukemia. Ann N Y Acad Sci (2012) 1259:95-103. doi:10.1111/ j.1749-6632.2012.06599.x

44. Hertog MG, Kromhout D, Aravanis C, Blackburn H, Buzina R, Fidanza F, et al. Flavonoid intake and long-term risk of coronary heart disease and cancer in the seven countries study. Arch Intern Med (1995) 155:381-6. doi:10.1001/archinte.1995.00430040053006

45. Vargas AJ, Sittadjody S, Thangasamy T, Mendoza EE, Limesand KH, Burd R. Exploiting tyrosinase expression and activity in melanocytic tumors: quercetin and the central role of p53. Integr Cancer Ther (2010) 10:328-40. doi:10.1177/1534735410391661

46. Gugler R, Leschik M, Dengler HJ. Disposition of quercetin in man after single oral and intravenous doses. Eur J Clin Pharmacol (1975) 9:229-34. doi:10.1007/bf00614022

47. Moon YJ, Wang L, Dicenzo R, Morris ME. Quercetin pharmacokinetics in humans. Biopharm Drug Dispos (2008) 29:205-17. doi:10.1002/bdd.605

48. Sampson L, Rimm E, Hollman PC, Vries JHD, Katan MB. Flavonol and flavone intakes in US health professionals. J Am Diet Assoc (2002) 102:1414-20. doi:10.1016/s0002-8223(02)90314-7

49. Murota K, Terao J. Antioxidative flavonoid quercetin: implication of its intestinal absorption and metabolism. Arch Biochem Biophys (2003) 417:12-7. doi:10.1016/s0003-9861(03)00284-4

50. Németh K, Plumb GW, Berrin J-G, Juge N, Jacob R, Naim HY, et al. Deglycosylation by small intestinal epithelial cell beta-glucosidases is a critical step in the absorption and metabolism of dietary flavonoid glycosides in humans. Eur J Nutr (2003) 42:29-42. doi:10.1007/s00394-0030397-3

51. Day AJ, Dupont M, Ridley S, Rhodes M, Rhodes MJ, Morgan MR, et al. Deglycosylation of flavonoid and isoflavonoid glycosides by human small intestine and liver $\beta$-glucosidase activity. FEBS Lett (1998) 436:71-5. doi:10.1016/s0014-5793(98)01101-6

52. Crespy V, Morand C, Manach C, Besson C, Demigne C, Remesy C. Part of quercetin absorbed in the small intestine is conjugated and further secreted in the intestinal lumen. Am J Physiol (1999) 277:120-6.

53. Graf BA, Ameho C, Dolnikowski GG, Milbury PE, Chen CY, Blumberg JB. Rat gastrointestinal tissues metabolize quercetin. J Nutr (2006) 136: $39-44$.

54. Egert S, Wolframm S, Bosy-Westphai A, Boesch-Saadatmandi C, Wagner AE, Frank J, et al. Daily quercetin supplementation dose-dependently increases plasma quercetin concentrations in healthy humans. J Nutr (2008) 138:1615-21.

55. Piskula MK, Németh K. Food content, processing, absorption and metabolism of onion flavonoids. Crit Rev Food Sci Nutr (2007) 47:397-409. doi:10.1080/10408390600846291

56. Graefe EU, Wittig J, Mueller S, Riethling A-K, Uehleke B, Drewelow B, et al. Pharmacokinetics and bioavailability of quercetin glycosides in humans. J Clin Pharmacol (2001) 41:492-9. doi:10.1177/00912700122010366

57. Lesser S, Cermak R, Wolffram S. Bioavailability of quercetin in pigs is influenced by the dietary fat content. J Nutr (2004) 134:1508-11.

58. Silberberg M, Morand C, Manach C, Scalbert A, Remesy C. Co-administration of quercetin and catechin in rats alters their absorption but not their metabolism. Life Sci (2005) 77:3156-67. doi:10.1016/j.lfs.2005.03.033

59. Eitsuka T, Tatewaki N, Nishida H, Nakagawa K, Miyazawa T. Synergistic anticancer effect of tocotrienol combined with chemotherapeutic agents or dietary components: a review. Int J Mol Sci (2016) 17:1605. doi:10.3390/ ijms17101605

60. Zhou Y, Zheng J, Li Y, Xu D-P, Li S, Chen Y-M, et al. Natural polyphenols for prevention and treatment of cancer. Nutrients (2016) 8:515. doi:10.3390/ nu8080515

61. Morand C, Crespy V, Manach C, Besson C, Demigné C, Rémésy C. Plasma metabolites of quercetin and their antioxidant properties. Am J Physiol (1998) 275:R212-9.

62. Omar K, Grant MH, Henderson C, Watson DG. The complex degradation and metabolism of quercetin in rat hepatocyte incubations. Xenobiotica (2014) 44:1074-82. doi:10.3109/00498254.2014.932032

63. Horton JA, Li F, Chung EJ, Hudak K, White A, Krausz K, et al. Quercetin inhibits radiation-induced skin fibrosis. Radiat Res (2013) 180:205-15. doi:10.1667/rr3237.1
64. Cai X, Fang Z, Dou J, Yu A, Zhai G. Bioavailability of quercetin: problems and promises. Curr Med Chem (2013) 20:2572-82. doi:10.2174/092986731 13209990120

65. Kawabata K, Mukai R, Ishisaka A. Quercetin and related polyphenols: new insights and implications for their bioactivity and bioavailability. Food Funct (2015) 6:1399-417. doi:10.1039/c4fo01178c

66. Biasutto L, Mattarei A, Sassi N, Azzolini M, Romio M, Paradisi C, et al. Improving the efficacy of plant polyphenols. Anticancer Agents Med Chem (2014) 14:1332-42. doi:10.2174/1871520614666140627150054

67. Wang L, Tu Y-C, Lian T-W, Hung J-T, Yen J-H, Wu M-J. Distinctive antioxidant and antiinflammatory effects of flavonols. J Agric Food Chem (2006) 54:9798-804. doi:10.1021/jf0620719

68. Rice-Evans CA, Miller NJ, Paganga G. Structure-antioxidant activity relationships of flavonoids and phenolic acids. Free Radic Biol Med (1996) 20:933-56. doi:10.1016/0891-5849(95)02227-9

69. Nam JS, Sharma A, Nguyen L, Chakraborty C, Sharma G, Lee S-S. Application of bioactive quercetin in oncotherapy: from nutrition to nanomedicine. Molecules (2016) 21:108. doi:10.3390/molecules21010108

70. Dhalla NS, Temsah RM, Netticadan T. Role of oxidative stress in cardiovascular diseases. J Hypertens (2000) 18:655-73. doi:10.1097/00004872200018060-00002

71. Uttara B, Singh A, Zamboni P, Mahajan R. Oxidative stress and neurodegenerative diseases: a review of upstream and downstream antioxidant therapeutic options. Curr Neuropharmacol (2009) 7:65-74. doi:10.2174/157015909787602823

72. Reddy VP, Zhu X, Perry G, Smith MA. Oxidative stress in diabetes and Alzheimer's disease. JAlzheimers Dis (2009) 16:763-74. doi:10.3233/ JAD-2009-1013

73. Locatelli F, Canaud B, Eckardt K-U, Stenvinkel P, Wanner C, Zoccali C. Oxidative stress in end-stage renal disease: an emerging threat to patient outcome. Nephrol Dial Transplant (2003) 18:1272-80. doi:10.1093/ndt/gfg074

74. Khansari N, Shakiba Y, Mahmoudi M. Chronic inflammation and oxidative stress as a major cause of age-related diseases and cancer. Recent Pat Inflamm Allergy Drug Discov (2009) 3:73-80. doi:10.2174/187221309787158371

75. Ranelletti FO, Maggiano N, Serra FG, Ricci R, Larocca LM, Lanza P, et al. Quercetin inhibits p21-RAS expression in human colon cancer cell lines and in primary colorectal tumors. Int J Cancer (2000) 85:438. doi:10.1002/ (sici) 1097-0215(20000201)85:33.3.co;2-6

76. Tanigawa S, Fujii M, Hou D-X. Stabilization of p53 is involved in quercetin-induced cell cycle arrest and apoptosis in HepG2 cells. Biosci Biotechnol Biochem (2008) 72:797-804. doi:10.1271/bbb.70680

77. Soengas MS, Lowe SW. Apoptosis and melanoma chemoresistance. Oncogene (2003) 22:3138-51. doi:10.1038/sj.onc.1206454

78. Awad HM, Boersma MG, Vervoort J, Rietjens IM. Peroxidase-catalyzed formation of quercetin quinone methide-glutathione adducts. Arch Biochem Biophys (2000) 378:224-33. doi:10.1006/abbi.2000.1832

79. Wätjen W, Michels G, Steffan B, Niering P, Chovolou Y, Kampkötter A, et al. Low concentrations of flavonoids are protective in rat H4IIE cells whereas high concentrations cause DNA damage and apoptosis. JNutr (2005) 135:525-31.

80. Tandler N, Mosch B, Pietzsch J. Protein and non-protein biomarkers in melanoma: a critical update. Amino Acids (2012) 43:2203-30. doi:10.1007/ s00726-012-1409-5

81. Boyle JL, Haupt HM, Stern JB, Multhaupt HA. Tyrosinase expression in malignant melanoma, desmoplastic melanoma, and peripheral nerve tumors. Arch Pathol Lab Med (2002) 126:2. doi:10.1043/0003-9985(2002) 1262.0.CO

82. Drexler I, Antunes E, Schmitz M, Wölfel T, Huber C, Erfle V, et al. Modified vaccinia virus Ankara for delivery of human tyrosinase as melanoma-associated antigen: induction of tyrosinase- and melanoma-specific human leukocyte antigen $\mathrm{A}^{\star} 0201$-restricted cytotoxic $\mathrm{T}$ cells in vitro and in vivo. Cancer Res (1999) 59:4955-63.

83. Riley PA, Cooksey CJ, Johnson CI, Land EJ, Latter AM, Ramsden CA. Melanogenesis-targeted anti-melanoma pro-drug development: effect of sidechain variations on the cytotoxicity of tyrosinase-generated ortho-quinones in a model screening system. Eur J Cancer (1997) 33:135-43. doi:10.1016/ s0959-8049(96)00340-1

84. Li J, Lee B, Lee AS. Endoplasmic reticulum stress-induced apoptosis: multiple pathways and activation of p53-up-regulated modulator of apoptosis 
(PUMA) and NOXA by p53. J Biol Chem (2006) 281:7260-70. doi:10.1074/ jbc.m509868200

85. Tanigawa S, Fujii M, Hou D. Action of Nrf2 and Keap1 in ARE-mediated NQO1 expression by quercetin. Free Radic Biol Med (2007) 42:1690-703. doi:10.1016/j.freeradbiomed.2007.02.017

86. Granado-Serrano AB, Martín MA, Bravo L, Goya L, Ramos S. Quercetin modulates Nrf2 and glutathione-related defenses in HepG2 cells: involvement of p38. Chem Biol Interact (2012) 195:154-64. doi:10.1016/j.cbi.2011.12.005

87. Schadich E, Hlaváč J, Volná T, Varanasi L, Hajdúch M, Džubák P. Effects of ginger phenylpropanoids and quercetin on Nrf2-ARE pathway in human BJ fibroblasts and HaCaT keratinocytes. Biomed Res Int (2016) 2016:1-6. doi:10.1155/2016/2173275

88. Ajit D, Simonyi A, Li R, Chen Z, Hannink M, Fritsche KL, et al. Phytochemicals and botanical extracts regulate NF- $\mathrm{kB}$ and Nrf2/ARE reporter activities in DI TNC1 astrocytes. Neurochem Int (2016) 97:49-56. doi:10.1016/j. neuint.2016.05.004

89. Chaiprasongsuk A, Onkoksoong T, Pluemsamran T, Limsaengurai S, Panich U. Photoprotection by dietary phenolics against melanogenesis induced by UVA through Nrf2-dependent antioxidant responses. Redox Biol (2016) 8:79-90. doi:10.1016/j.redox.2015.12.006

90. Suzuki T, Motohashi H, Yamamoto M. Toward clinical application of the Keap1-Nrf2 pathway. Trends Pharmacol Sci (2013) 34:340-6. doi:10.1016/j. tips.2013.04.005

91. Asher G, Bercovich Z, Tsvetkov P, Shaul Y, Kahana C. 20S proteasomal degradation of ornithine decarboxylase Is regulated by NQO1. Mol Cell (2005) 17:645-55. doi:10.1016/j.molcel.2005.01.020

92. Asher G, Lotem J, Kama R, Sachs L, Shaul Y. NQO1 stabilizes p53 through a distinct pathway. Proc Natl Acad Sci U S A (2002) 99:3099-104. doi:10.1073/ pnas.052706799

93. Asher G, Lotem J, Cohen B, Sachs L, Shaul Y. Regulation of p53 stability and p53-dependent apoptosis by NADH quinone oxidoreductase 1. Proc Natl Acad Sci U S A (2001) 98:1188-93. doi:10.1073/pnas.98.3.1188

94. Asher G, Lotem J, Sachs L, Kahana C, Shaul Y. Mdm-2 and ubiquitin-independent 553 proteasomal degradation regulated by NQO1. Proc Natl Acad Sci U S A (2002) 99:13125-30. doi:10.1073/pnas.202480499

95. Asher G, Lotem J, Tsvetkov P, Reiss V, Sachs L, Shaul Y. p53 hot-spot mutants are resistant to ubiquitin-independent degradation by increased binding to NAD(P)H:quinone oxidoreductase 1. Proc Natl Acad Sci U S A (2003) 100:15065-70. doi:10.1073/pnas.2436329100

96. Asher G, Lotem J, Sachs L, Shaul Y. p53-dependent apoptosis and NAD(P) H:quinone oxidoreductase 1. Methods Enzymol (2004) 382:278-93. doi:10.1016/s0076-6879(04)82016-0

97. Anwar A, Dehn D, Siegel D, Kepa JK, Tang LJ, Pietenpol JA, et al. Interaction of human $\mathrm{NAD}(\mathrm{P}) \mathrm{H}$ :quinone oxidoreductase 1 (NQO1) with the tumor suppressor protein p53 in cells and cell-free systems. J Biol Chem (2003) 278:10368-73. doi:10.1074/jbc.m211981200

98. Lu M, Miller P, Lu X. Restoring the tumour suppressive function of $\mathrm{p} 53$ as a parallel strategy in melanoma therapy. FEBS Lett (2014) 588:2616-21. doi:10.1016/j.febslet.2014.05.008

99. Itoh K, Chiba T, Takahashi S, Ishii T, Igarashi K, Katoh Y, et al. An Nrf2/Small Maf heterodimer mediates the induction of phase II detoxifying enzyme genes through antioxidant response elements. Biochem Biophys Res Commun (1997) 236:313-22. doi:10.1006/bbrc.1997.6943

100. Nioi P, Mcmahon M, Itoh K, Yamamoto M, Hayes JD. Identification of a novel Nrf2-regulated antioxidant response element (ARE) in the mouse $\mathrm{NAD}(\mathrm{P})$ $\mathrm{H}$ :quinone oxidoreductase 1 gene: reassessment of the ARE consensus sequence. Biochem J (2003) 374:337-48. doi:10.1042/bj20030754

101. Dinkova-Kostova AT, Holtzclaw WD, Wakabayashi N. Keap1, the sensor for electrophiles and oxidants that regulates the phase 2 response, is a zinc metalloprotein. Biochemistry (2005) 44:6889-99. doi:10.1021/bi047434h

102. Ogura T, Tong KI, Mio K, Maruyama Y, Kurokawa H, Sato C, et al. Keap1 is a forked-stem dimer structure with two large spheres enclosing the intervening, double glycine repeat, and C-terminal domains. Proc Natl Acad Sci U S A (2010) 107:2842-7. doi:10.1073/pnas.0914036107

103. Tong KI, Padmanabhan B, Kobayashi A, Shang C, Hirotsu Y, Yokoyama S, et al. Different electrostatic potentials define ETGE and DLG motifs as hinge and latch in oxidative stress response. Mol Cell Biol (2007) 27:7511-21. doi:10.1128/mcb.00753-07
104. Rius M, Lyko F. Epigenetic cancer therapy: rationales, targets and drugs. Oncogene (2012) 31:4257-65. doi:10.1038/onc.2011.601

105. Sarkar S, Horn G, Moulton K, Oza A, Byler S, Kokolus S, et al. Cancer development, progression, and therapy: an epigenetic overview. Int J Mol Sci (2013) 14:21087-113. doi:10.3390/ijms141021087

106. Marzese DM, Hoon DS. Emerging technologies for studying DNA methylation for the molecular diagnosis of cancer. Expert Rev Mol Diagn (2015) 15:647-64. doi:10.1586/14737159.2015.1027194

107. Lee WJ, Shim JY, Zhu BT. Mechanisms for the inhibition of DNA methyltransferases by tea catechins and bioflavonoids. Mol Pharmacol (2005) 68:1018-30. doi:10.1124/mol.104.008367

108. Sharma V, Kumar L, Mohanty SK, Maikhuri JP, Rajender S, Gupta G. Sensitization of androgen refractory prostate cancer cells to anti-androgens through re-expression of epigenetically repressed androgen receptor synergistic action of quercetin and curcumin. Mol Cell Endocrinol (2016) 431:12-23. doi:10.1016/j.mce.2016.04.024

109. Tan S, Wang C, Lu C, Zhao B, Cui Y, Shi X, et al. Quercetin is able to demethylate the p16INK4a gene promoter. Chemotherapy (2009) 55:6-10. doi:10.1159/000166383

110. Zheng NG, Wang JL, Yang SL, Wu JL. Aberrant epigenetic alteration in Eca9706 cells modulated by nanoliposomal quercetin combined with butyrate mediated via epigenetic-NF-KB signaling. Asian Pac J Cancer Prev (2014) 15(11):4539-43. doi:10.7314/APJCP.2014.15.11.4539

111. Lee WJ, Chen YR, Tseng TH. Quercetin induces FasL-related apoptosis, in part, through promotion of histone $\mathrm{H} 3$ acetylation in human leukemia HL-60 cells. Oncol Rep (2011) 25:583-91. doi:10.3892/or.2010.1097

112. Bishayee K, Khuda-Bukhsh AR, Huh S-O. PLGA-Loaded gold-nanoparticles precipitated with quercetin downregulate HDAC-Akt activities controlling proliferation and activate p53-ROS crosstalk to induce apoptosis in hepatocarcinoma cells. Mol Cells (2015) 38:518-27. doi:10.14348/molcells. 2015.2339

113. Boesch-Saadatmandi C, Loboda A, Wagner AE, Stachurska A, Jozkowicz A, Dulak J, et al. Effect of quercetin and its metabolites isorhamnetin and quercetin-3-glucuronide on inflammatory gene expression: role of miR-155. J Nutr Biochem (2011) 22:293-9. doi:10.1016/j.jnutbio.2010.02.008

114. Boesch-Saadatmandi C, Wagner AE, Wolffram S, Rimbach G. Effect of quercetin on inflammatory gene expression in mice liver in vivo - role of redox factor 1, miRNA-122 and miRNA-125b. Pharmacol Res (2012) 65:523-30. doi:10.1016/j.phrs.2012.02.007

115. Milenkovic D, Deval C, Gouranton E, Landrier J-F, Scalbert A, Morand C, et al. Modulation of miRNA expression by dietary polyphenols in apoE deficient mice: a new mechanism of the action of polyphenols. PLoS One (2012) 7:e29837. doi:10.1371/journal.pone.0029837

116. Okano M, Xie S, Li E. Cloning and characterization of a family of novel mammalian DNA (cytosine-5) methyltransferases. Nat Genet (1998) 19:219-20. doi:10.1038/890

117. Sharpless E, Chin L. The INK4a/ARF locus and melanoma. Oncogene (2003) 22:3092-8. doi:10.1038/sj.onc.1206461

118. Burd R, Panayi ND, Breshears ES, Mendoza EE. Aberrant death pathways in melanoma. In: Davids L, editor. Recent Advances in the Biology, Therapy and Management of Melanoma. INTECH Open Access Publisher (2013). Available from: http://www.intechopen.com/books/ recent-advances-in-the-biology-therapy-and-management-of-melanoma/ aberrant-death-pathways-in-melanoma

119. Venza M, Visalli M, Biondo C, Lentini M, Catalano T, Teti D, et al. Epigenetic regulation of p14ARF and p16INK4A expression in cutaneous and uveal melanoma. Biochim Biophys Acta (2015) 1849:247-56. doi:10.1016/j. bbagrm.2014.12.004

120. Jonsson A, Tuominen R, Grafström E, Hansson J, Egyhazi S. High frequency of p16INK4A promoter methylation in NRAS-mutated cutaneous melanoma. J Invest Dermatol (2010) 130:2809-17. doi:10.1038/jid.2010.216

121. Unamuno BD, Palanca S, Botella R. Update on melanoma epigenetics. Curr Opin Oncol (2015) 27:420-6. doi:10.1097/cco.0000000000000217

122. Galdieri L, Vancura A. Acetyl-CoA carboxylase regulates global histone acetylation. J Biol Chem (2012) 287:23865-76. doi:10.1074/jbc.m112.380519

123. Libra M, Malaponte G, Navolanic PM, Gangemi P, Bevelacqua V, Proietti L, et al. Analysis of BRAF mutation in primary and metastatic melanoma. Cell Cycle (2005) 4:1382-4. doi:10.4161/cc.4.10.2026 
124. Nazarian R, Shi H, Wang Q, Kong X, Koya RC, Lee H, et al. Melanomas acquire resistance to B-RAF(V600E) inhibition by RTK or N-RAS upregulation. Nature (2010) 468:973-7. doi:10.1038/nature09626

125. Wagle N, Emery C, Berger MF, Davis MJ, Sawyer A, Pochanard P, et al. Dissecting therapeutic resistance to RAF inhibition in melanoma by tumor genomic profiling. J Clin Oncol (2011) 29:3085-96. doi:10.1200/ jco.2010.33.2312

126. Shi H, Hong A, Kong X, Koya RC, Song C, Moriceau G, et al. A novel AKT1 mutant amplifies an adaptive melanoma response to BRAF inhibition. Cancer Discov (2014) 4:69-79. doi:10.1158/2159-8290.cd-13-0279

127. Rafiq RA, Quadri A, Nazir LA, Peerzada K, Ganai BA, Tasduq SA. A potent inhibitor of Phosphoinositide 3-Kinase (PI3K) and mitogen activated protein (MAP) kinase signalling, quercetin (3,3', ' $^{\prime}$.5,7-pentahydroxyflavone) promotes cell death in ultraviolet (UV)-B-irradiated B16F10 melanoma cells. PLoS One (2015) 10:1-20. doi:10.1371/journal.pone.0131253

128. Sun ZJ, Chen G, Hu X, Zhang W, Liu Y, Zhu L-X, et al. Activation of $\mathrm{PI} 3 \mathrm{~K} / \mathrm{Akt} / \mathrm{IKK}-\mathrm{alpha/NF-kappaB}$ signaling pathway is required for the apoptosis-evasion in human salivary adenoid cystic carcinoma: its inhibition by quercetin. Apoptosis (2010) 15:850-63. doi:10.1007/s10495-0100497-5

129. Pozsgai E, Bellyei S, Cseh A, Boronkai A, Racz B, Szabo A, et al. Quercetin increases the efficacy of glioblastoma treatment compared to standard chemoradiotherapy by the suppression of PI-3-Kinase-Akt pathway. Nutr Cancer (2013) 65:1059-66. doi:10.1080/01635581.2013. 810291

130. Song NR, Chung M-Y, Kang NJ, Seo SG, Jang TS, Lee HJ, et al. Quercetin suppresses invasion and migration of H-Ras-transformed MCF10A human epithelial cells by inhibiting phosphatidylinositol 3-kinase. Food Chem (2014) 142:66-71. doi:10.1016/j.foodchem.2013.07.002

131. Hu J, Wang J, Wang G, Yao Z, Dang X. Pharmacokinetics and antitumor efficacy of DSPE-PEG2000 polymeric liposomes loaded with quercetin and temozolomide: analysis of their effectiveness in enhancing the chemosensitization of drug-resistant glioma cells. Int J Mol Med (2016) 37:690-702. doi:10.3892/ijmm.2016.2458

132. Kumari A, Yadav SK, Pakade YB, Singh B, Yadav SC. Development of biodegradable nanoparticles for delivery of quercetin. Colloids Surf B Biointerfaces (2010) 80:184-92. doi:10.1016/j.colsurfb.2010.06.002
133. Sahoo NG, Kakran M, Shaal LA, Li L, Müller RH, Pal M, et al. Preparation and characterization of quercetin nanocrystals. J Pharm Sci (2011) 100:2379-90. doi:10.1002/jps.22446

134. Tran TH, Guo Y, Song D, Bruno RS, Lu X. Quercetin-containing self-nanoemulsifying drug delivery system for improving oral bioavailability. J Pharm Sci (2014) 103:840-52. doi:10.1002/jps.23858

135. Lockhart JN, Stevens DM, Beezer DB, Kravitz A, Harth E. Dual drug delivery of tamoxifen and quercetin: regulated metabolism for anticancer treatment with nanosponges. JControl Release (2015) 220:751-7. doi:10.1016/ j.jconrel.2015.08.052

136. Pimple S, Manjappa AS, Ukawala M, Murthy RS. PLGA nanoparticles loaded with etoposide and quercetin dihydrate individually: in vitro cell line study to ensure advantage of combination therapy. Cancer Nanotechnol (2012) 3:25-36. doi:10.1007/s12645-012-0027-y

137. Li N, Sun C, Zhou B, Xing H, Ma D, Chen G, et al. Low concentration of quercetin antagonizes the cytotoxic effects of anti-neoplastic drugs in ovarian cancer. PLoS One (2014) 9:e100314. doi:10.1371/journal.pone.0100314

138. Milenkovic D, Jude B, Morand C. miRNA as molecular target of polyphenols underlying their biological effects. Free Radic Biol Med (2013) 64:40-51. doi:10.1016/j.freeradbiomed.2013.05.046

139. Bartel DP. MicroRNAs: genomics, biogenesis, mechanism, and function. Cell (2004) 116:281-97. doi:10.1016/S0092-8674(04)00045-5

140. Lam TK, Shao S, Zhao Y, Marincola F, Pesatori A, Bertazzi PA, et al. Influence of quercetin-rich food intake on microRNA expression in lung cancer tissues. Cancer EpidemiolBiomarkersPrev (2012)21:2176-84.doi:10.1158/1055-9965. epi-12-0745

Conflict of Interest Statement: The authors declare that the research was conducted in the absence of any commercial or financial relationships that could be construed as a potential conflict of interest.

Copyright (C) 2016 Harris, Donovan, Branco, Limesand and Burd. This is an open-access article distributed under the terms of the Creative Commons Attribution License (CC BY). The use, distribution or reproduction in other forums is permitted, provided the original author(s) or licensor are credited and that the original publication in this journal is cited, in accordance with accepted academic practice. No use, distribution or reproduction is permitted which does not comply with these terms. 